\title{
MULTICULTURALISMO E (NOVOS) DIREITOS ENTRE DEMOCRACIA E CONSTITUCIONALISMO LATINO-AMERICANO
}

\author{
MULTICULTURALISM AND (NEW) BETWEEN RIGHTS \\ DEMOCRACY AND HISPANIC CONSTITUTIONALISM
}

José Osório do Nascimento Neto *

Resumo: As diversas dimensões que caracterizam o emergente Constitucionalismo do século XXI - política, social, econômica, ambiental e cultural - transformam em desafio as ações do Estado, que implicam os processos decisórios coletivos da sociedade contemporânea. É nesse ambiente que o presente artigo tem por objetivo levantar e discutir apontamentos interdisciplinares ao estudo da Democracia e do Constitucionalismo Latino-americano, prestigiando o pensamento crítico sobre e necessária relação entre multiculturalismo e os (novos) direitos como a educação em Direitos Humanos. Para que isso seja possível, são trabalhadas, inicialmente, as noções de multiculturalismo e tensões no Estado Constitucional. É diante de sociedades plurais que são (re)tencionadas as representaões políticas das Instituições Democráticas, exigindo-se, naturalmente, um espaço contramajoritário como exercício de soberania popular. Como resposta a estas condições, é proposto o estudo qualitativo sobre inclusão social e educação em Direitos Humanos como mecanismos viáveis de atuação de um Estado Democrático de Direito. Em outras palavras, é justamente diante do ambiente latino-americano que se pode compreender os (novos) direitos como mecanismos de enfrentamento de tensões entre democracia e constitucionalismo emergente. E mais: é preciso saber como canalizar as instituições para a promoção de mecanismos de inclusão social e construção da cidadania. Sequencialmente ao referido raciocínio, são apontados, criticamente, alguns desafios deste século, para uma educação plural e cidadã como exemplo de (novos) direitos, entre os quais se destaca a educação em Direitos Humanos. Esta análise crítica justifica-se pela necessidade do avanço do conhecimento científico no ambiente de estudo metodológico como forma de tutela estatal diante do multiculturalismo latino-americano.

Palavras-Chave: multiculturalismo; educação; direitos humanos; democracia; constitucionalismo latino-americano.

Abstract: The various dimensions that characterize the emerging Constitutionalism twentyfirst century - political, social, economic, environmental and cultural - turn to challenge the State's actions, involving the collective decision-making processes of contemporary society. It is in this environment that this article aims to raise and discuss interdisciplinary notes the study of Democracy and Constitutionalism Latin American and prestige critical thinking about and necessary relationship between multiculturalism and the (new) rights such as education in human rights. For this to be possible, they are worked initially, the multiculturalism of notions and tensions in the Constitutional State. It is in front of plural societies that are (re) tensioned political representations of Democratic Institutions, demanding, of course, a contramajoritário space as popular sovereignty exercise. In response to these conditions, the qualitative study on social inclusion and education in human rights as viable mechanisms of action of a democratic state is proposed. In other words, it is just before the Latin American environment that one can understand the (new) rights as stress coping

\footnotetext{
* Professor convidado dos Cursos de Especialização em 'Economia e Meio Ambiente' e 'Direito Ambiental' do Programa de Educação Continuada em Ciências Agrárias da Universidade Federal do Paraná. Pesquisador do grupo PÁTRIAS do Mestrado em Direito do UniBrasil. E-mail: osorio.nascimento@gmail.com
} 
mechanisms among emerging democracy and constitutionalism. Plus, you need to know how to channel the institutions to promote mechanisms for social inclusion and empowerment. Sequentially to that reasoning, are singled out, critically, some challenges of this century, for a plural and citizenship education as an example of (new) rights, among which stands out education in human rights. This critical analysis is justified by the need for the advancement of scientific knowledge in the methodological study environment as a form of state supervision on the Latin American multiculturalism.

Keywords: multiculturalism; education; human rights; democracy; Latin American constitutionalism.

\section{INTRODUÇÃO}

Como contribuição acadêmica ao estudo da Democracia e do Constitucionalismo Latino-americano, apresenta-se à Revista da Faculdade de Direito da UFG - Universidade Federal de Goiás este artigo científico, que tem por objetivo prestigiar o pensamento crítico sobre e necessária relação entre multiculturalismo e os (novos) direitos, decorrentes deste início de Século XXI.

Democracia e constitucionalismo estão em pauta desde o surgimento do Estado Moderno (MAMED, 2015 p. 101-120), numa relação nem sempre linear (SOUZA FILHO, 2015, p. 88). A partir do Estado Contemporâneo, a tensão existente entre um e outro se intensifica, em especial, com o renascer das sociedades plurais - com novos direitos e novos sujeitos de direito, bem como com a judicialização da política no âmbito do Judiciário, provocando conflitos com os poderes Legislativo e Executivo. Em meio à referida tensão, novas soluções vão surgindo e, consequentemente, outros debates sobre desenhos institucionais do Estado, rediscussão de mecanismos de exercício da soberania popular e da legitimidade dos poderes instituídos vão se intensificando, para além dos três poderes.

Em que pese não haver, pelo menos, neste início do Século XXI, uma resposta imediata à tensão em comento, alguns itens deste debate precisam ser elevados à categoria de premissas para que o assunto avance no tempo. Sob a perspectiva sociocultural, o que talvez seja interessante na relação entre constitucionalismo e democracia, levantam-se justamente as demandas contemporâneas que revigoram o debate teórico e que chamam por novas práticas a eduação em direitos humanos. Para que isto seja possível, algumas justificativas e recortes se fazem necessários à metodologia científica deste trabalho propositivo e interdisciplinar.

A questão do tempo e suas terminologias são importantes. Em primeiro lugar, há se lembrar de que o constitucionalismo tradicional se caracterizou por ser eminentemente 
normativo. O constitucionalismo contemporâneo, por sua vez, compreendido a partir da Revolução dos Estados Unidos, com o estabelecimento de um texto normativo de hierarquia superior em forma de um documento solene, tem como conteúdos necessários aspectos relacionados à limitação e organização do poder e dos órgãos de soberania, com a construção de um Estado cuja ação está vinculada ao Direito. ${ }^{1}$

Alinhado à ideia de que a superação do modelo tradicional das estruturas jurídicas importa em reorganização das relações entre os poderes; e, à percepção de que as atividades dos Poderes que representam Institucionalmente o Estado Democrático de Direito devem acordar com os novos parâmetros impostos pelo neoconstitucionalismo, esta pesquisa está centrada numa proposição interdisciplinar ${ }^{2}$ como possível articulação entre Constitucionalismo e Democracia. Não se trata, consequentemente, de teorias da Justiça/Democracia, judicialização da política, ativismo ou legitimidade do controle judicial das leis e nem das análises sobre as possibilidades e limites da hermenêutica constitucional.

No caso do constitucionalismo latino-americano, que outorgam à natureza o status de sujeito de direito (MORAES; FREITAS, 2013, p. 57), questiona-se a admissão sob qualquer flexibilização dos capitais natural e humano, devendo o capital econômico submeterse à necessidade de manutenção do equilíbrio socioambiental. É nesse contexto que se insere a proposta de estudo do multiculturalismo e a forma como se pode canalizar as instituições para a promoção de mecanismos de inclusão social e construção da cidadania.

Premissas teóricas também são importantes. Por um lado, sabe-se que John H. ELY, Jürgen HABERMAS e Carlos Santiago NINO, defensores da chamada democracia procedimental, argumentam que os valores da sociedade só podem ser definidos num debate democrático realizado pela própria sociedade e não pelo Poder Judiciário, que não teria legitimidade por não ter sido eleito. Por outro lado, a doutrina brasileira foi influenciada por teóricos da teoria substantiva norte-americana, em que impera o judicial review, que permite um controle de valores da Constituição por parte do Poder Judiciário, de modo a rever as leis emanadas pelo Legislativo. Aqui, Ronald DWORKIN sustenta que o judicial review deve procurar garantir direitos por intermédio de decisões de princípios e não de política. Nesse ambiente, serão estudadas as noções de multiculturalismo e as tensões existentes no Estado Constitucional. 


\section{MULTICULTURALISMO E TENSÕES NO ESTADO CONSTITUCIONAL}

A democracia continua sendo a palavra chave dos regimes políticos. A primeira ideia quando se fala em democracia é a de governo da maioria. Não obstante, apesar do voto majoritário ser considerado pedra fundamental no sistema da democracia representativa, o mesmo não é suficiente para garantir decisões corretas ou mesmo resultados justos e racionais, uma vez que o princípio majoritário não assegura a igualdade política. Ou seja, o resultado do voto majoritário representa a voz dos vencedores e não necessariamente o bem comum ou o interesse de todos, e a questão está em saber se apenas o procedimento democrático seria capaz de assegurar um resultado justo e correto para todos (KOZICKI; BARBOZA, 2008, p. 151).

Por esta razão, nos Estados Constitucionais atuais, o governo da maioria deve conviver com os direitos das minorias, geralmente elevados à categoria de direitos fundamentais, já que o pluralismo e as minorias se fazem presentes, e todos, absolutamente todos, devem ser protegidos (KOZICKI; BARBOZA, 2008, p. 151). O ideal moderno da igualdade e da autodeterminação impõe uma relação entre governantes e governados, tomada ora como identidade, ora mediada pela representação política. Em regra, no entanto, o "governo do povo" torna-se o "governo autorizado pelo povo" e a instrumentalização da cidadania (BELLO, 2012, p. 13; NASCIMENTO NETO, 2014. p. 103) e da soberania popular, em uma democracia contemporânea, faz-se pelo instituto da representação política (SALGADO, 2011, p. 107).

$\mathrm{O}$ fato de diferentes culturas postularem o mesmo direito de exercerem, num mesmo país, as suas diferenças, exige das democracias uma espécie de mediação entre a igualdade e a diferença, entre constâncias da maioria e devires criativos das minorias, na medida em que sua universalidade comporta (ALCALÁ, 2005, P. 57).

E é aí que está a tensão entre democracia e constitucionalismo, na medida em que este acaba por limitar a liberdade de deliberação dos representantes eleitos pelo povo que, por sua vez, não podem elaborar leis que afrontem direitos fundamentais das minorias, ou mesmo individuais, elencados na Constituição (KOZICKI; BARBOZA, 2008, p. 151).

Para Jon ELSTER (1999, p. 38), o constitucionalismo se justifica como um ato de pré-compromisso que serve para proteger decisões imprudentes. Aqui, o papel das limitações constitucionais seria o de impedir que a sociedade modifique sua opinião em questões 
importantes baseada apenas em paixões, autoengano e histerias, que podem determinar que uma maioria temporal estabeleça alterações lamentadas posteriormente. Assim, a noção central é de que a assembleia constituinte aprova as leis fundamentais que são a base para todas as gerações seguintes. De modo que, só a assembleia constituinte é realmente um ator político, no sentido forte de la politique politisante; todas as gerações seguintes estão restritas a la politique politisée.

A partir dessa constatação, sugere uma noção de que através da assembleia constituinte a sociedade se amarra estabelecendo poderes de decisão sobre alguns temas ao judiciário e criando super-maiorias para a modificação da Constituição, propondo o 'paradoxo da democracia', segundo o qual: cada geração quer ser livre para obrigar a sua sucessora, enquanto não é obrigada pelos seus predecessores. No entanto, como se percebe, trata-se de discussão que pode ser enfrentada com base em argumentos intertemporais, pois, sob esta perspectiva, a Constituição é legítima somente porque todas as alternativas disponíveis carecem de legitimidade, dando a entender que a geração seguinte não tem obrigação de se sentir amarrada, nem possui o direito de legitimamente amarrar seus sucessores.

No entanto, como se sabe, o constitucionalismo do positivismo oitocentista é um constitucionalismo frágil que se limita a estabelecer o esquema básico da ordem política e de suas instituições, atribuindo competências e determinando procedimentos, um constitucionalismo das regras do jogo, dos limites que não podem ser ultrapassados, dos direitos que não podem ser transgredidos, um constitucionalismo de mínimos que estabelece um marco de convivência baseado na autonomia dos indivíduos nas esferas social e política (CAMPUZANO, 2012, p. 148).

Na Suprema Corte norte-americana, por outro lado, afirmou-se um conjunto de técnicas de autorestrição no exercício de sua função de revisão da legislação (judicial selfrestraint). Com isso, tinha-se por objetivo harmonizar o exercício das funções estatais dentro de uma lógica de freios e contrapesos. Os seguintes elementos destacam-se nessa doutrina de autocontenção: (i) cases and controversies; (ii) standing to sue; (iii) precedent; (iv) comity; (v) political questions. Gustavo Ferreira SANTOS (2006, p. 49) bem explica:

Com a primeira técnica, a controvérsia a ser analisada deve estar devidamente delimitada, uma vez que é função do Judiciário solucionar conflitos na aplicação da lei e não meramente emitir opiniões. A segunda técnica diz respeito à exigência de que prove a parte que requer a decisão da Suprema Corte o seu interesse direto na solução do conflito. Com a terceira técnica, o órgão de decisão apresenta-se vinculado a decisões anteriores, apesar de serem tais decisões passíveis de 
reapreciação, funcionando o precedente como uma espécie de guia às atividades, em razão da adoção da regra do stare decisis. A quarta técnica destaca o papel da Suprema Corte no sistema judicial da Federação, exigindo harmonização com os demais tribunais, o que faz necessária a exaustão dos recursos aos tribunais estaduais, como condição para que se exercite o direito de recurso ao tribunal superior. Na última técnica, que tem suscitado maiores polêmicas, a doutrina das questões políticas, exige a Corte que tratem os casos levados à decisão da Suprema Corte de questões jurídicas stricto sensu, sendo presumida a constitucionalidade dos atos do legislador.

Com nuanças que representam as diferenças entre os sistemas constitucionais dos Estados Unidos e do Brasil, todos esses elementos, de alguma forma, refletiram-se na jurisprudência do Supremo Tribunal Federal ou nas normas que regem o nosso controle de constitucionalidade das leis. Ao ser explícita na Constituição a função de sua guarda, o Judiciário recebe uma atribuição política inegável. É preciso que o juiz constitucional tenha sempre isso claro na hora de decidir. O exercício dessa função deve ser observado e controlado pela sociedade, com consciência da dimensão política das questões constitucionais. Isso é da essência de sistemas que permitem ao Juiz revisar a legislação (SANTOS, 2006, p. 51).

Ao tratar da ponderação, da jurisdição constitucional e da representação em sua obra "Constitucionalismo discursivo", Robert ALEXY (2011, p. 155-166) coloca o discurso jurídico como proposta de fundamentação racional das decisões. Em outras palavras, uma decisão que se vale da ponderação ganha a sua legitimidade a partir da escolha feita e expressa em fundamentos racionais.

Para Cristina QUEIROZ (1996, p. 477), essa realidade de uma concepção de direitos, que vai além do conceito de código e que traz o Poder Judiciário para o centro do constitucionalismo, implica um conceito de Direito que engloba, "além das normas, os princípios, os valores e as formas de argumentação, que servem de referência às decisões jurídicas". Passa-se da dogmática à pragmática. Em outras palavras, a Jurisdição Constitucional tem, em sua atividade, um relacionamento estreito com o elemento político. Por isso, é prudente que se cuide para fugir de qualquer tentação de abuso desse poder.

Nas palavras de Eneida Desiree SALGADO (2011, p. 125), “em nome de uma representação 'adequada' da vontade do eleitorado o Poder Judiciário acabou por impor mais um filtro entre o povo e o poder. (...) e em cenário de intensa fluidez ideológico-partidária, (...) esse intermediário apenas aumenta a impossibilidade de determinação do conteúdo da relação de representação". Com isso, se poderia reforçar, segundo Hanna Fenichel PITKIN 
(1967, p. 239), que "nenhum sistema institucional pode garantir a essência, a substância da representação".

No entanto, em que pese a tentativa de mitigar uma relação de representatividade por meio de uma Instituição Democrática - e responsável por valores substantivos das Sociedades - existem dois pontos que precisam ser trabalhados: (i) a tomada da responsabilidade pelo cidadão, que precisa compreender o seu papel na democracia e se dar conta das demais formas de interferência na formação da vontade política (sendo uma delas, por meio da educação); (ii) a legitimidade das Instituições do Estado Democrático de Direito que precisam ser democratizadas ${ }^{3}$.

Por um lado, a legitimidade demanda uma reconsideração profunda em duplo sentido: em primeiro lugar, porque não pode seguir sendo concebida como uma característica extrajurídica da norma, mas sim, é preciso que fique associada a uma concepção dinâmica de validade e eficácia; em segundo lugar, porque a legitimidade extrajurídica não pode seguir desvinculada da legitimidade política (CAMPUZANO, 2012, p. 143-166). Seria inócuo, por exemplo, atribuir ao Poder Judiciário e, logicamente aos seus ministros, a chamada apoliticidade (em sentido amplo). Portanto, anular ou reduzir a legitimidade de Instituições Democráticas não parece ser o caminho mais acertado para reduzir a tensão entre Constitucionalismo e Democracia.

Por outro lado, este mesmo debate exige uma conexão imediata entre constitucionalismo e participação política, pois a base de todo regime constitucional é a expressão da vontade cidadã através de procedimentos legalmente previstos. Assim, sociedades plurais e suas respectivas cidadanias, enquanto centros de imputação de direitos difusos, somente adquirem sentido em uma ordem democrática através do exercício efetivo de participação democrática; de modo que a Constituição, enquanto modelo normativo que expressa uma vontade coletiva de convivência democrática, alcança sua máxima expressão através da participação como exercício de soberania popular (LEWIS, 1996, p. 1-30).

Com isso, o novo desenho institucional das relações plurais no constitucionalismo contemporâneo deve ficar sob o guarda-chuva protetor da legitimidade democrática, em conjunto com a participação como exercício de soberania popular. Difícil tarefa que recai sobre a mesma pergunta de outrora: como resolver este emblema? Como sustentar a atuação do Legislativo e/ou do Judiciário, na atividade de editar normas, criar direitos e afirmar a constitucionalidade das normas promulgadas? 
O desenvolvimento de uma estrutura institucional de Estado Democrático de Direito, dotada de mecanismos adequados de representação, respaldada em critérios de legitimidade jurídico-político; somado à democratização destas mesmas Instituições, com participação nos processos de tomada de decisões, que refletem em demandas substantivas da Constituição, podem ser possíveis a partir do comportamento do multiculturalismo.

Neste caso, o multiculturalismo pode ser compreendido ou como fator social ou como teoria. $\mathrm{O}$ primeiro diz respeito à convivência de grupos distintos dentro de um mesmo território; a segunda possibilidade, por sua vez, toma o caráter normativo abrindo propostas para a solução dos conflitos provenientes da convivência entre diferentes pessoas ou grupos culturais que buscam a coexistência em um mesmo território. Nesse sentido, recomenda-se, fortemente, a leitura de SILVA, 2006; CORTINA, 2002; Taylor 1993. Aqui, existe a necessidade do reconhecimento público das diferenças para a sobrevivência dos diferentes grupos culturais em uma sociedade multicultural.

Ao se referir ao Estado (em sentido amplo) como detentor do Poder, levantou-se, num primeiro momento, a tensão existente entre Constitucionalismo e Democracia, evolvendo a discussão entre o exercício da soberania popular e a legitimidade das decisões das Instituições Democráticas que compõe o ordenamento jurídico brasileiro.

A partir deste contexto, propõe-se, aqui, a educação em direitos humanos como possível ponto de articulação entre o Constitucionalismo e a Democracia, considerando-se o comportamento institucional como modalidade de atuação do Estado Democrático de Direito e sua respectiva capacidade de integração entre Sociedades plurais e o Estado.

Quem se aproxima bastante desta (nova) proposta como instrumento de legitimidade das instituições democráticas no estado contemporâneo são as referencias constitucionais latino-americanas. Apenas a título exemplificativo, sabe-se que: da Constituição de Weimar às constituições europeias do pós-guerra, o constitucionalismo social transforma profundamente a relação entre Estado e sociedade. O catálogo de direitos fundamentais foi ampliado, abrangendo diversos direitos a prestações e à proteção da relação de trabalho. O Executivo assume um papel de destaque "pela necessidade de assegurar a governabilidade em um sistema que se legitima, fundamentalmente, por suas prestações sociais e pela necessidade de que o Estado se situe como eixo dos pactos sociais que efetuam entre si os partidos com os agentes econômicos e sociais". (ASENSI SABATER, 1996, p. 43). 
O objetivo de integração nas democracias constitui o núcleo de suporte de proposta classificatória das democracias oferecida por Francisco VIOLA (2006, p. 55). Assim, defendendo um possível exemplo de correlação com o escopo de demonstrar que o liame entre o constitucionalismo e o multiculturalismo (característico também de um constitucionalismo latino-americano) reclama uma redefinição do modo de compreensão dos instrumentos democráticos para atender aos novos padrões do constitucionalismo contemporâneo, levanta-se a chamada integração de novos direitos e novos sujeitos de direito nas Sociedades Plurais. Explica-se abaixo.

Para Luigi FERRAJOLI (2006, p. 16), “o estado constitucional de direito é a única ordem institucional em que é possível realizar o projeto garantista. Por meio dos vínculos substanciais da positivação do "dever ser" constitucional impõe-se ao próprio direito positivo". Em outras palavras, "a existência de um Estado Constitucional de Direito é essencial não somente no aspecto formal e material, mas também substancial para as condições de validez das normas, sendo que a validade está condicionada pela coerência de seus significados e conteúdos com os princípios constitucionais" (TAVARES NETO; BARBOSA, 2012, 79).

Ao tratar, por exemplo, sobre os postulados do constitucionalismo e da democracia, bem como sobre a tensão existente entre estes, em especial, diante da questão pluralista das comunidades tradicionais, Kerlay Lizane ARBOS e Carlos Frederico Marés de SOUZA FILHO (2010, p. 57-58) comentam com propriedade que:

\begin{abstract}
a democracia ainda é a fomentadora das discussões, pois permite o acontecimento de debates e questionamentos. E refletir, de bater e discutir sobre a questão do multiculturalismo, compreendendo a importância da diversidade cultural presente nas sociedades contemporâneas, é um ato de extrema urgência no cenário da modernidade. É justamente a partir do questionamento da democracia pelo multiculturalismo que nasce a necessidade de se reconhecer a diversidade cultural que constitui o espaço público de uma sociedade. Ou seja, a necessidade de reconhecimento da diversidade cultural pelas instituições públicas das sociedades contemporâneas. Logo, a diferença é essencial, dentro do multiculturalismo, para a definição da democracia como um espaço genuinamente heterogêneo. (grifos próprios).
\end{abstract}

Ainda, ao estabelecer uma relação entre os sistemas jurídicos constitucionais e a perspectiva socioambiental, Carlos Marés de SOUZA FILHO (2003, p. 93) reforça:

ao lado do individualismo homogeneizador, reconheceu-se um pluralismo repleto de diversidade social, cultural e natural, numa perspectiva que se pode chamar de 
socioambiental. Os sistemas jurídicos constitucionais, antes fechados ao reconhecimento da pluriculturalidade e da multietnicidade, foram reconhecendo, um a um, que os países do continente têm uma variada formação étnica e cultural, e que cada grupo humano que esteja organizado segundo sua cultura e viva segundo a sua tradição, em conformidade com a natureza da qual participa, tem direito à opção de seu próprio desenvolvimento. (grifos próprios).

Como bem colocado, este aspecto do multiculturalismo precisa ser discutivo e rediscutido, é nele onde mora o palco de conflitos perenes e de desconstrução da democracia. Daí, a necessidade de um avanço em direção à interculturalidade, à capacidade de composição dos conflitos ou, mesmo, à prevenção de sua criação, através do diálogo intercultural, da quebra das barreiras e muros, físicos ou identitários, culturais e ideológicos (SANTOS; EDLER, 2016, p. 193).

A partir deste contexto, o Estado pode reafirmar a promoção do constitucionalismo e da democracia, na medida em que assim estabelece as condições para o autogoverno do povo, assegurando, consequentemente, que todos os pontos de vista sejam expostos a todos, respeitando as diferenças, vale dizer, quem tem menos voz - as minorias requerem espaços contramajoritários para serem ouvidas de forma igual às maiorias e seus espaços (CHUEIRI, 2013, p. 558), sendo justamente por meio desta atuação estatal que se caracteriza a educação em direitos humanos como mecanismo de exercício de soberania popular.

Em que pese a questão do direito das minorias, dentro de um governo de maiorias, elevar a tensão já existente entre democracia e constitucionalismo, supõem-se, mutuamente, serem "equiprimordiais e co-originários", constituindo um ao outro como afirma Menelick de CARVALHO NETTO (2003, p. 82-83): “a democracia só é democrática se for constitucional" e "o constitucionalismo só é constitucional se for democrático".

Dessa forma - e a título exemplificativo, a participação das comunidades tradicionais nas discussões e debates favorece a construção de um país e de um regime político democrático com base num pluralismo social, político e cultural que considera e respeita as diferentes concepções e a diversidade cultural (ARBOS; SOUZA FILHO, 2010, p. 72), morando aí a atuação seja do Poder Legislativo, seja do Poder Judiciário, na atividade de editar normas, criar direitos e afirmar a constitucionalidade das normas promulgadas.

Daí a importância, sob uma perspectiva socioconstitucional, da educação em direitos humanos. Em sentido amplo, como meio de reafirmação da democracia e do constitucionalismo; e, em sentido estrito, através da reorganização de instituições 
democráticas e procedimentos adequados, que impliquem na efetiva participação de todos. Para tanto, não é preciso "força" ou "mão forte", mas povo e Instituições democráticas fortificadas no espírito do socioconstitucionalismo. Isso significa vincular, teórica e praticamente, a educação em direitos humanos à articulação entre Democracia e Constitucionalismo contemporâneo.

3 (NOVOS) DIREITOS COMO MECANISMOS DE ENFRENTAMENTO DE TENSÕES ENTRE DEMOCRACIA E CONSTITUCIONALISMO EMERGENTE

Qualquer institucionalização das demandas multiculturais deve passar necessariamente pelo debate em torno dos direitos sociais, como premissas para uma condição cidadã e afirmando a própria dimensão integrativa e interdependente de tais direitos na conformação de uma tutela integral da dignidade da pessoa humana no horizonte políticojurídico de um socioambientalismo (SOUZA-LIMA, 2014, p.180; SARLET; FENSTERSEIFER, 2014, p. 31; SANTILLI, 2005, p. 31).

Reforçando o que já havia sido dito, no caso do constitucionalismo latinoamericano, que outorgam à natureza o status de sujeito de direito (MORAES; FREITAS, 2013, p. 57), questiona-se fortemente a admissão sob qualquer flexibilização dos capitais natural e humano, devendo o capital econômico submeter-se à necessidade de manutenção do equilíbrio socioambiental. É nesse contexto que se insere a proposta de estudo do multiculturalismo e a forma como se pode canalizar as instituições para a promoção de mecanismos de inclusão social e construção da cidadania.

A abordagem transdisciplinar do conceito subjacente sugere que são caracterizados por eventos de origem histórica, com consequências comumente agravadas pela ação antrópica, que superam a capacidade de controle do homem, causando perturbações nefastas no meio (ambiente, social e cultural) e consubstanciando impactos na coletividade de severidade elevada (ALVINO-BORBA, 2013, p. 46).

Erivaldo Moreira BARBOSA e Maria de Fátima BARBOSA complementam esse entendimento, ao afirmar que uma nova leitura se faz necessária: enquanto a dimensão hermenêutica interpreta os textos jurídicos e os documentos não jurídicos, a dimensão sistêmica interliga as componentes jurídicas, sociais, econômicas, técnicas, filosóficas, éticas e ecológicas (BARBOSA, 2013, p. 183). Atos normativos feitos com remendos e retalhos 
acabam se revelando piores que as legislações que os antecederam, não contribuindo com uma possível solução.

Então, partindo-se do pressuposto de que a educação consiste num direito social e de que a expressão "educação em direitos humanos" pode ser tratada como um instrumento jurídico capaz de contribuir com as diversas formas de tutela estatal, este artigo também tem por objeto a apresentação crítica de breves traços metodológicos que podem interferir no processo de aprendizagem, bem como na verificação avaliativa da educação. O cotidiano que envolve a prática docente e seus pressupostos, em especial, sobre as variáveis que podem refletir nas tarefas propostas em sala de aula, tais como: habilidades afetivas; habilidades cognitivas; interação dos participantes; e, comunicação entre professores e alunos.

A identificação de habilidades afetivas como uma necessidade prévia à avaliação de uma política pública social, típica da prática docente é de suma importância, pois absorve, em sua essência, a ideia de receptividade, que perpassa, em primeiro lugar, pela consciência plena de se resgatar o conhecimento, tendo a percepção e a sensibilidade de que é preciso avançar no tempo. Com isso, a concordância, o consentimento e adesão à possibilidade de novos caminhos de ensino-aprendizagem, precisam, necessariamente, convergir com os valores de disposição e compromissos com outros seres sociais, também detentores de direitos e deveres com seus próximos.

Em outras palavras, trata-se de acreditar que a sala de aula é, também, um espaço de ensino-aprendizagem, onde há retomada de conhecimento e espaço para conceituação, debate e aceitação (ou não) de um dado valor. Aqui, é possível destacar, entre outros exemplos: (i) a segurança emocional do professor, que independentemente de sua formação, precisa trabalhar com opinião diversa ao que pensa; e, (ii) a maturidade do aluno, ideia muito bem trabalhada a partir na Dissertação de Mestrado de Luci Ferraz de MELLO ${ }^{4}$ sobre educação.

A partir desta classificação, em conjunto com a compreensão dos diferentes tipos de inteligência, segundo Howard GARDNER ${ }^{5}$, professor de Cognição e Educação na Universidade de Harvard, é possível se demonstrar, mais detalhadamente, como as habilidades afetivas podem interferir na relação entre professor, aluno e turma, levando-se em consideração a aprendizagem de cada uma das partes dessa relação.

Assim, considerando-se os níveis da classificação de Bloom como a recepção, a resposta, a avaliação, a organização de valores e a internalização, pode-se levantar, a título 
exemplificativo, a complexidade para conhecer o motivo pelo qual um aluno poderia se excluir da participação de uma sala de aula, incorrendo (ou não) um ônus sobre a avaliação formal da disciplina.

Em outras palavras, novamente, se insere a noção de recepção (Bloom) e de inteligência interpessoal (Gardner). Ora, se a ideia de receptividade perpassa pela consciência plena de se resgatar o conhecimento, dando-se conta de fatos, predisposição para ouvir e atenção seletiva, pode-se dizer, então, que a ausência intencional pode ser motivada por uma timidez (forma inteligência interpessoal avaliada como baixa), inabilidade com a linguagem escrita (muito comum, inclusive, na área do Direito), falta de naturalidade para relacionar-se com o meio ou falta de vontade/interesse em participar, em colaborar consigo e como o grupo na construção individual e coletiva do conhecimento.

Assim, em que pese este ser apenas um caso exemplificativo, também é importante lembrar que, na relação entre professor, aluno e turma, as habilidades afetivas também envolvem outros aspectos como resposta, valorização, organização, complexo de valores, assim como as diversas inteligências em sala de aula, como a lógico-matemática, intrapessoal, naturalista, vísuo-espacial, corpo-cinestésica, musical e linguista, onde se encaixa com tranquilidade a Educação Jurídica.

\section{DESAFIOS PARA UMA EDUCAÇÃO MULTICULTURAL ENTRE OS (NOVOS) DIREITOS DO SÉCULO XXI}

É exatamente aqui que se nota a necessidade do avanço do conhecimento científico no ambiente de estudo metodológico para avaliação de políticas educacionais. Primeiro, porque existe, sim, uma necessidade prévia de identificação de habilidades afetivas para a avaliação de uma política pública sociocultural. Não se trata de um mero questionamento subjetivo, que, claro, poderia dar margem a distorções num processo de avaliação minimamente confiável, mas de ponto metodológico que não pode ser ignorado ao se perguntar se existe ou não vontade de ambas as partes envolvidas na construção do conhecimento, razão pela qual a afetividade e a afinidade em relação à educação em direitos humanos precisam ser identificadas de forma imediata.

De forma sequencial, as habilidades cognitivas precisam ser tratadas como exigência de tutela estatal na prática de educação, pois é justamente por meio de uma percepção de formação qualitativa e de seu respectivo conhecimento que o professor R. Fac. Dir. UFG, v. 40, n.2, p. 112-132, jul. / dez. 2016

ISSN 0101-7187 
consegue, por exemplo, captar a reação da turma e suas possíveis dificuldades durante o aprendizado.

Somada a estes pontos tem-se o mecanismo de interação entre os discentes como ponto de observação metodológico para a avaliação de uma política pública educacional, lembrando que, por se tratar de uma linguagem não verbal, a ausência de uma participação ativa, efetiva e intensa entre os sujeitos que compõem a turma também pode desestimular o aluno e/ou até mesmo o grupo. Isso significa, em outras palavras, que referida política pública social, voltada notadamente à educação, provavelmente só terá sucesso se houver a percepção real de que o grupo caminha junto durante o processo de aprendizagem.

Nesse mesmo ambiente, para a avaliação de uma política social no ambiente de aprendizagem, não se pode ignorar, em nenhuma hipótese, a comunicação entre professores e alunos, isso porque referido ambiente apresenta peculiaridades específicas como a linguagem não verbal. A postura do professor se traduz de certa forma como mecanismo indutor de uma política pública eficiente e qualitativa.

E, por último, nestes breves traços metodológicos, para avaliação de uma política pública de educação, não se pode esquecer de que cada aluno tem seu próprio ritmo, cabendo ao professor fazer um planejamento individual-coletivo, seja em relação ao tempo, seja em relação à interdisciplinaridade do conteúdo propriamente dito. Fomentar uma conexão entre teoria e prática, é conceder ao aluno a possibilidade de demonstrar não apenas o que foi capaz de absorver como informação transmitida, mas também de expor seu pensamento, de forma a contribuir para o desenvolvimento da coletividade em que está inserido, justificando-se, portanto, mais uma tutela do Estado para o desenvolvimento da educação como direito social.

Em síntese, o professor precisa ter um repertório de conhecimentos e experiências bem diversificado, que se traduz, por sua vez, num passaporte para que ele apresente novas possibilidades diante da prática docente, incluindo-se aí a sala de aula e a temática dos direitos humanos, como ponto de partida para a resolução de conflitos socioambientais. Exatamente nesta linha, a inquietude, a curiosidade e os questionamentos reforçam a disposição do professor para sempre aprender continuamente, contribuindo de forma ativa para a construção e reconstrução do conhecimento, sendo este respaldado por um processo de ensino-aprendizado qualificado, bem organizado, planejado e estruturado. 


\section{CONSIDERAÇÕES FINAIS}

Em resposta à problemática apresentada, podem ser extraídas algumas conclusões articuladas, com as quais se pretende contribuir para o debate desse importante tema da atualidade:

- em linhas gerais, a democracia significa o povo decidindo as questões politicamente relevantes da sua comunidade, inclusive, os conteúdos da constituição; e, o constitucionalismo, limites à soberania popular;

- $\quad$ a Constituição se autoimpõe como manifestação da soberania popular e do poder constituinte, vinculando ambos. Com isso, a conjugação entre constitucionalismo e democracia absorve outra discussão: o exercício da soberania popular e o poder constituinte. O constitucionalismo, em vez de frear o poder constituinte, exibe-o e o reafirma quando garante e protege os compromissos históricos e socioculturais conquistados ao longo do tempo.

- com o constitucionalismo contemporâneo, "se desfazem" os sistemas jurídicos constitucionais antes fechados ao reconhecimento da pluriculturalidade e da multietnicidade (TÁRREGA; GONÇALVES, 2016), surgindo uma postura constitucionalista forte, na qual a constituição não se basta como parâmetro orientador da política, mas se faz efetiva, com a fiscalização de uma jurisdição constitucional atuante e expansiva;

- $\quad$ o fenômeno da judicialização da política afirma a expansão do Poder Judiciário no estado contemporâneo, provocando conflitos com os poderes Legislativo e Executivo, ao mesmo tempo em que "minorias" - a partir de Sociedades Plurais, passam a exigir, naturalmente, um espaço contramajoritário. O reconhecimento judicial dos direitos de “minorias", ao contrário de significar uma ofensa ao princípio da separação dos poderes ou uma usurpação da função legislativa pelo poder judiciário, representa o reforço da própria democracia, desde que, claro, sob a premissa da democratização da jurisdição constitucional;

- $\quad$ assim, diante de um pretenso clico vicioso de tensão entre constitucionalismo e democracia, que parece insolúvel, soluções exigem novos desenhos institucionais, rediscussão de mecanismos de exercício da soberania popular e da legitimidade dos poderes instituídos em meio aos conflitos socioambientais. 
- por um lado, as desigualdades e segregações sociais produzem condições desfavoráveis à participação cidadã. Por outro lado, a participação sociopolítica produz capital social e cultural, habilitando os cidadãos na disputa em torno do exercício dos direitos de cidadania, e, portanto, em torno da própria inclusão social. Os diferentes arranjos institucionais que coordenam e regulam a relação entre governo e sociedade interferem diretamente na tensão entre direitos, constituição de identidades e participação cidadã (SANTOS; EDLER, 2016, p. 193).

- como proposta de estudo, coloca-se a educação em direitos humanos como modalidade de atuação de um Estado Democrático de Direito para articular essa tensão entre constitucionalismo e democracia. Trata-se de uma educação, sob a perspectiva de multiculturalismo, dentro de um Estado Constitucional, que investiga os papeis do Direito na concepção e construção de sociedades plurais, por meio de desenhos institucionais que demonstrem o compromisso entre os dois polos da relação, seja em relação ao exercício de soberania popular, seja em relação à legitimidade de Instituições Democráticas, ambas capazes de criar direitos e afirmar a constitucionalidade das normas promulgadas;

- a avaliação de uma política sociocultural no ambiente de aprendizagem, não se pode ignorar, em nenhuma hipótese, a comunicação entre professores e alunos, isso porque referido ambiente apresenta peculiaridades específicas. Aqui, o professor precisa ter um repertório de conhecimentos e experiências bem diversificado, que se traduz, por sua vez, num passaporte para que ele apresente novas possibilidades diante da prática docente, incluindo-se aí a sala de aula e a temática dos direitos humanos, como ponto de partida para a resolução de conflitos socioculturais.

Em síntese, sob a perspectiva socioconstitucional, parte-se do pressuposto que diz respeito ao nexo interno entre a soberania popular e o exercício de direitos, que está na base da ação do Estado Democrático de Direito, inclusive, para suas próprias Instituições, morando justamente aí a educação em direitos humanaos para a articulação entre Democracia e Constitucionalismo Latino-americano. 


\section{REFERÊNCIAS}

ALCALÁ, J. Alberto del Real. Problemas de gestión de la diversidad cultural en un mundo plural. In: RUIZ, Ruiz Ramón; et al. (Editores). Derechos fundamentales, valores y multiculturalismo. Madrid: Dykinson, 2005.

ALVINO-BORBA, Andreilcy; MATA-LIMA, Abel; MATA-LIMA, Herlander. PINHEIRO, Adilson; ALMEIDA, José António. Impactos dos desastres naturais nos sistemas ambiental e socioeconômico: o que faz a diferença? Ambiente \& Sociedade, São Paulo, v. 16, n. 3, p. 46, jul./set. 2013.

ARBOS, Kerlay Lizane; SOUZA FILHO, Carlos Frederico Marés. Constitucionalismo x democracia: o multiculturalismo e as comunidades tradicionais. Prismas: Dir., Pol. Publ. e Mundial., Brasília, v. 7, n. 1, p. 57-58, jan./jun. 2010.

BARBOSA, Erivaldo Moreira; NÓBREGA, Maria de Fátima. O Direito Ambiental em perspectiva: da hermenêutica-sistêmica ao saber ambiental. Veredas do Direito, Belo Horizonte, v. 10, n. 20, p. 183, jul./dez. 2013.

BELLO, Enzo. A cidadania no constitucionalismo latino-americano. Caxias do Sul: Educs, 2012.

CAMPUZANO, Alfonso de Julios; NASCIMENTO, Valéria Ribas do. Por quem dobram os sinos? Reflexões sobre neoconstitucionalismo e ciência jurídica. Revista de Direitos Fundamentais e Democracia, Curitiba, v. 12, n. 12, p. 148, jul./dez. 2012.

CARVALHO NETTO, Menelick de. Racionalização do ordenamento jurídico e democracia: a consolidação das leis e o aperfeiçoamento da democracia. Revista Brasileira de Estudos Políticos, Belo Horizonte, n. 88, p. 82-83, dez. 2003.

CHUEIRI, Vera Karam de; RAMOS, Diego Motta. Liberdade de expressão, constitucionalismo e democracia: meios de comunicação de massa e regulação. Revista Jurídica da Presidência, Brasília, v. 14, n. 104, p. 558, out. 2012/jan. 2013.

CORTINA, A. Ciudadanía Intercultural, [s/p.]. CONILL, J. (Coord.). Glosario para uma sociedad intercultural.Valência: Bancaja, 2002.

DERANI, Cristiane. Direito Ambiental Internacional e globalização. In: RAMINA, Larissa Liz Odreski; FRIEDRICH, Tatyana Scheila. (Org.). Direito Internacional multifacetado: direitos humanos, meio ambiente e segurança. v. II. Curitiba: Juruá, 2014. p. 13-33.

ELSTER, Jon. Introducción. In: ELSTER, Jon; SLAGSTAD, Rune. (Org.). Constitucionalismo y democracia. Estudio introductorio de Alejandro Herrera M. Ciudad del México: Colegio Nacional de Ciencias Políticas y Administración Pública, 1999. p. 38.

FACHIN, Melina Girardi. Direitos humanos e desenvolvimento. Rio de Janeiro: Renovar, 2014. 
GARDNER, Howard. Para cada pessoa, um tipo de educação. In: Fronteiras do Pensamento. Disponível em: <http://www.youtube.com/watch?v=tLHrC1ISPXE>. Acesso em: 07 de ago. 2013.

GOMES, Eduardo Biacchi; ROSSI, Amélia Sampaio. Neoconstitucionalismo e a (re)significação dos direitos humanos fundamentais. Revista da Ajuris, Porto Alegre, v. 41, n. 133 , p. 63-82, mar. 2014.

KOZICKI, Katya; BARBOZA, Estefânia Maria de Queiroz. Jurisdição constitucional brasileira: entre constitucionalismo e democracia, 2007. Sequencia (Florianópolis), v. 56, p. 151, jun. 2008.

LEWIS, Norman. Choice and the legal order: rising above politics. Cambridge: Cambridge Univ., 1996. p. 1-30.

LEXY, Robert. Constitucionalismo discursivo. Tradução de Luís Afonso Heck. 3. ed. Porto Alegre: Livraria do Advogado, 2011. p. 155-166.

MAMED, Danielle de Ouro. La modernidad y la mercantilización de la naturaleza: buscando nuevos caminos frente a la crisis socioambiental. Revista de Derechos Humanos y Estudios Sociales, v. 1, p. 101-120, 2015.

MELLO, Luci Ferraz de. Educomunicação na educação: o diálogo a partir das mediações do tutor. 306 f. (Dissertação de Mestrado). Programa de Pós-Graduação em Ciência da Comunicação. Escola de Comunicação da Universidade de São Paulo. 2010.

MORAES, Germana de Oliveira e FREITAS, Raquel Coelho. O novo constitucionalismo latino-americano e o giro ecocêntrico da Constituição do Equador de 2008: os direitos de Pachamama e o bem viver (sumak kawsay). In: WOLKMER, Antonio Carlos e MELO, Milena Petters. Constitucionalismo latino-americano: tendências contemporâneas. Curitiba: Juruá, 2013.

NASCIMENTO NETO, José Osório do. Cidadania e regulação no Estado Constitucional: apontamentos da democracia para a implementação de políticas públicas no Brasil. In: KNOERR, Viviane Coêlho de Sellos. (Org.). Diálogos (im)pertinentes: Estado, Direito e Democracia. Curitiba: Instituto Memória, 2014. p. 103-121.

OLIVEIRA, Fábio Corrêa Souza de; STRECK, Lenio. Um Direito Constitucional Comum Latino-Americano: por uma teoria geral do novo constitucionalismo latino-americano. Revista do Instituto de Hermenêutica Jurídica, ano 10, n. 11. Belo Horizonte: Fórum, 121 $151,2012$.

PITKIN, Hanna Fenichel. The concept of representation. Berkeley: University of California Press, 1967.

QUEIROZ, Cristina. Constituição, constitucionalismo e democracia. In: MIRANDA, Jorge (Org.). Perspectivas constitucionais: nos 20 anos da Constituição de 1976. Coimbra: Coimbra, 1996. 
ROSSI, Amélia do Carmo Sampaio. Neoconstitucionalismo: ultrapassagem ou releitura do positivismo jurídico? Curitiba: Juruá, 2011.

SALGADO, Eneida Desiree. A representação política e sua mitologia. In: RUIZ, Jorge Fernández. (Org.). Estudios de Derecho Electoral. México: Universidad Nacional Autónoma de México, 2011.

SANTILLI, Juliana. Socioambientalismo e novos direitos: proteção jurídica à diversidade biológica e cultural. São Paulo: Peirópolis, 2005.

SANTOS, Gustavo Ferreira. Neoconstitucionalismo e democracia. Revista de Informação Legislativa, Brasília, a. 43 n. 172, p. 49. out./dez. 2006.

SANTOS, André Leonardo Copetti; SANTOS, Evelyne Freistedt Copetti. Democracia em cidades multiculturais. Ressignificando os sistemas de tomadas de decisão públicas à luz dos direitos humanos das minorias. Revista Direitos fundamentais Democracia, Curitiba, v. 19, n. 19, p. 169-209, jan./jun. 2016.

SARLET, Ingo Wolfgang; FENSTERSEIFER, Tiago. Direito Constitucional Ambiental: estudos sobre a Constituição, os direitos fundamentais e a proteção do ambiente. 4. ed. São Paulo: Revista dos Tribunais, 2014.

SILVA, Larissa. O multiculturalismo e a política de reconhecimento de Charles Taylor. Revista NEJ - Novos Estudos Jurídicos, Univali, v. 11, n. 2, p. 313-322, jul/dez. 2006.

SOUZA FILHO, Carlos Frederico Marés de. El nuevo constitucionalismo en América Latina y los derechos de los pueblos indígenas. In: SANCHEZ, Enrique (org.). Derecho de los pueblos indígenas en las constituciones de América Latina: Bolívia, Brasil, Colombia, Ecuador, Guatemala, México, Nicarágua, Panamá, Paraguay, Peru y Venezuela. Santafé de Bogotá: Disloque, 1996.

SOUZA FILHO, Carlos Frederico Marés de. De como a natureza foi expulsa da modernidade. Revista Crítica do Direito, São Paulo, v. 66, p. 88-105, 2015.

SOUZA FILHO, Carlos Frederico Marés de. Multiculturalismo e direitos coletivos. In: SANTOS, Boaventura de Souza (Org.). Reconhecer para libertar: os caminhos do cosmopolitismo multicultural. Rio de Janeiro: Civilização Brasileira, 2003.

SOUZA-LIMA, José Edmilson de; MARTINI, Karlla Maria. Licenciamento ambiental: uma proposta de (re)leitura em um estado de direito socioambiental. Revista Direitos Fundamentais e Democracia, Curitiba, v. 16, n. 16, p. 180, jul./dez. 2014.

TÁRREGA, Maria Cristina Vidotte Blanco; GONÇALVES, Daniel Diniz. Estados plurinacionais como luta insurgente emancipadora. R. Fac. Dir. UFG, v. 40, n.1, p. 74 - 94, jan. / jun. 2016. http://dx.doi.org/10.5216/rfd.v40i1.39314. Acesso em: 10. ago. 2016. 
TAVARES NETO, José Querino; BARBOSA, Claudia Maria. Democratização da jurisdição constitucional: uma análise a partir de Pierre Bourdieu. Revista da Faculdade de Direito da UFG, v. 36, n. 1, p. 60-84, jan./jun. 2012.

TAYLOR, Crarles. El multiculturalismo y "la política del reconocimiento". México, Fondo de Cultura Económica, 1993.

1 Sobre o histórico do Constitucionalismo, recomenda-se: ROSSI, Amélia do Carmo Sampaio. Neoconstitucionalismo: ultrapassagem ou releitura do positivismo jurídico? Curitiba: Juruá, 2011.

${ }^{2}$ Fazendo referência a Carlos Santiago NINO e a Roberto GARGARELLA, uma alternativa a ser explorada é a de percorrer um caminho comum às duas noções, de tal forma a ressaltar as peculiaridades e qualidades do constitucionalismo e da democracia. Em outras palavras, o fato de que um é constitutivo do outro, sem que isso signifique necessariamente o fim da tensão ou um certo apaziguamento ingênuo entre ambos.

3 Especialmente sobre democratização da jurisdição constitucional, recomenda-se: TAVARES NETO, José Querino; BARBOSA, Claudia Maria. Democratização da jurisdição constitucional: uma análise a partir de Pierre Bourdieu. Revista da Faculdade de Direito da UFG, v. 36, n. 1, p. 60-84, jan./jun. 2012.

${ }^{4}$ Nesse sentido, recomenda-se: MELLO, Luci Ferraz de. Educomunicação na educação: o diálogo a partir das mediações do tutor. 306 f. (Dissertação de Mestrado). Programa de Pós-Graduação em Ciência da Comunicação. Escola de Comunicação da Universidade de São Paulo. 2010.

${ }^{5}$ Nesse sentido, ver: GARDNER, Howard. Para cada pessoa, um tipo de educação. In: Fronteiras do Pensamento. Disponível em: 〈http://www.youtube.com/watch?v=tLHrC1ISPXE〉. Acesso em: 07 de ago. 2013. 
Artigo recebido em 22 de agosto de 2016 e aceito em 10 de dezembro de 2016 